\title{
A OBJETIFICAÇÃO DO INSTRUMENTO: LENDO A VIRAVOLTA HEIDEGGERIANA A PARTIR DA CRÍTICA À METAFÍSICA ${ }^{1}$
}

\author{
Sabrina Ruggeri ${ }^{2}$ \\ Pontifícia Universidade Católica do Rio Grande do Sul (PUCRS) \\ (i) https://orcid.org/0000-0002-9906-2206
}

\begin{abstract}
RESUMO:
Este trabalho pretende desenvolver um breve confronto com Ser e Tempo a partir do conceito de instrumento [Zeug], cuja análise deve contribuir para a articulação de uma leitura quanto ao sentido da Viravolta [die Kehre] heideggeriana dos anos 30. Nossa proposta é a de desvelar o caráter metafísico de Ser e Tempo a partir do diagnóstico de um modo de relacionamento exclusivamente pragmático e instrumental com as coisas de nosso cotidiano, o qual incorre em última análise no problema da objetificação. Para esse diagnóstico, devemos manter como horizonte o próprio projeto heideggeriano de crítica à metafísica: a constatação da objetificação da coisa enquanto instrumento é tornada possível a partir da segunda fase do pensamento heideggeriano (inaugurada pela Viravolta), onde a crítica da metafísica é articulada como história do esquecimento do Ser. Neste momento, a análise das bases metafísicas da Modernidade revela uma postura específica a partir da qual o sujeito moderno teria se orientado pela dominação do ente, uma mesma postura a ser identificada na análise do instrumento em Ser e Tempo. Assim, segundo uma leitura imanente ao pensamento heideggeriano, porque orientada pela continuidade de seu projeto crítico, podemos entender a Viravolta como um aprofundamento da tarefa de superação da metafísica, cuja exigência trata de ultrapassar tanto o relacionamento objetificado com as coisas de nossos mundos cotidianos como a postura moderna de dominação.
\end{abstract}

PALAVRAS-CHAVE: Martin Heidegger; Metafísica; Modernidade; Viravolta; Ser e Tempo.

\section{THE OBJECTIFICATION OF THE EQUIPMENT: READING THE}

\footnotetext{
${ }^{1}$ Este trabalho faz parte de nossa pesquisa de Mestrado.

${ }^{2}$ Mestranda em Filosofia pela Pontifícia Universidade Católica do Rio Grande do Sul (PUCRS), Rio Grande do Sul - Brasil. Bolsista CNPq. Email: sabrinarufrei@ gmail.com.
} 


\title{
HEIDEGGERIAN TURN FROM THE CRITIQUE OF METAPHYSICS
}

\begin{abstract}
:
This paper intends to develop a brief confrontation with Being and Time from the concept of equipment [Zeug], whose analysis should contribute to the articulation of a reading of the meaning of the heideggerian Turn [die Kehre] in the 30's. Our proposal is to unveiling the metaphysical character of Being and Time from the diagnosis of a way of relationship exclusively pragmatic and instrumental with the things of our everyday, which ultimately incurring in the problem of objectification. To this diagnosis, we should keep as a horizon the very heideggerian project of critique to the metaphysics: the finding of the objectification of the thing as equipment is made possible from the second phase of the heideggerian thinking (inaugurated by the Turn), where the critique of metaphysics is articulated as the history of oblivion of Being. At this moment, the analysis of the metaphysical basis of Modernity discloses a specific stance from which the modern subject would have guided himself to the domination of beings, one same stance to be identified in the analysis of the equipment in Being and Time. So from an immanent reading to the heideggerian thinking, because guided by the continuity of his critical project, we can understand the Turn as a deepening of the task of overcoming of metaphysics, whose demand should surpass both the objectification of relationship with the things of our everyday worlds and the modern stance of domination.
\end{abstract}

KEYWORDS: Martin Heidegger; Metaphysics; Modernity; Turn; Being and Time.

Os conceitos de instrumento [Zeug] e manualidade [Zuhandenheit] cumprem a importante tarefa de no contexto de Ser e Tempo articular o modo cotidiano pelo qual o ser-aí se relaciona com o mundo das coisas e consigo mesmo, um relacionamento de cunho prático, portanto, que encontra no trato ocupado com diferentes utensílios e na execução de diversas tarefas a realização do modo de ser cotidiano do ser-aí. Contudo, um olhar mais atento à descrição da postura do ser-aí diante desta espécie de objeto revela um aspecto controverso quanto à compreensão que aí está em jogo do sentido do humano e de seu lugar no mundo. A leitura que pretendemos desenvolver quanto ao ser do instrumento em Ser e Tempo, desvelando um possível caráter metafísico da obra, articula-se de um modo imanente ao pensamento heideggeriano, segundo uma avaliação em retrospectiva: à luz da Viravolta [die Kehre] dos anos 30 e da nova configuração conceitual que com ela emerge. A inflexão da Viravolta, portanto, deve cumprir com o movimento de transição para uma segunda 
fase no pensamento de Heidegger, onde a centralidade da pergunta pelo sentido do Ser dá lugar a uma crítica da metafísica como história do esquecimento do Ser. A Viravolta significa assim uma mudança essencial no projeto heideggeriano quanto à perspectiva adotada para a interpelação do Ser: abandona-se o foco no ser humano e sua temporalidade finita (sua Zeitlichkeit), central para a estruturação das categorias fenomenológicas de Ser e Tempo, em nome de uma inversão que desloca o centro da análise para o próprio Ser e sua temporalidade mais originária, a qual Heidegger teria chamado de temporaneidade [Temporalität] (GIACOIA JUNIOR, 2013, p. 85). Neste segundo momento da filosofia heideggeriana se visa diretamente ao Ser, a articulação fundamental de sua questão consiste na procura da expressão de sua verdade ao longo de sua própria história, isto é, junto das interpretações do ente de cada época: o projeto heideggeriano pós-viravolta investiga os resquícios impensados da verdade do Ser que permanecem encobertos a cada nova abertura histórica do ente.

Assim, nossa análise deve iniciar pelo diagnóstico do caráter metafísico do conceito de instrumento apresentado em Ser e Tempo, cuja articulação se desdobra em dois traços principais: a estrutura exclusivamente pragmática e instrumental do mundo do ser-aí e o decorrente relacionamento objetificador deste mesmo ser-aí com as coisas do seu mundo. A concepção de coisa própria a Ser e Tempo (ao menos as coisas com as quais nos relacionamos de modo prático no dia-a-dia, aquelas coisas que se apresentam como utensílios para nossos afazeres), deste modo, é pensada segundo a noção de instrumento [Zeug] cujo ser se revela de modo primeiro na ocupação [Besorgen] cotidiana do ser-aí, isto é, enquanto ferramenta empregada pelo ser humano na execução de uma tarefa que é previamente estabelecida como o fim da própria ocupação. Um dos principais movimentos de crítica à Modernidade em Ser e Tempo aparece a partir daqui: Heidegger deseja construir uma análise fenomenológica que se desvinculasse daquele modelo exclusivamente epistêmico que contrapunha o objeto como "mera coisa" diante do sujeito, quer dizer, da coisa que supostamente se apresentava de imediato como res extensa, como objeto físico capaz de ocupar um lugar no espaço. Numa crítica clara à filosofia cartesiana, Heidegger escolhe priorizar o modo cotidiano como as coisas aparecem para nós no interior de nosso próprio mundo, o que ele deve chamar de mundo ambiente [Umwelt], isto é, as significações que as coisas adquirem quando vêm ao encontro de um ser-aí essencialmente ocupado e preocupado com seus projetos - a doação primeira das coisas no contexto de Ser e Tempo assenta sobre um relacionamento de cunho prático.

\section{A objetificação do instrumento: Ser e Tempo e o problema da metafísica}

A ideia central para a concepção de coisa como instrumento em Ser e Tempo, portanto, é a de que o significado que as coisas adquirem em seu 
vir-à-presença no interior de nosso mundo encontra sempre respaldo nos projetos aos quais nós nos dedicamos em nosso cotidiano, nas necessidades práticas que nos envolvem e nos ocupam no dia-a-dia, em última análise, na utilidade que estas coisas incorporam enquanto instrumentos para o nosso modo de vida. Deste modo, Heidegger concebe que o que é próprio ao instrumento, a sua instrumentalidade [Zeughaftigkeit], reside na exigência de que ele apareça sempre a partir da configuração de uma totalidade na qual o instrumento constitui um momento particular: "Ao ser de instrumento pertence sempre cada vez um todo-instrumental, no qual esse instrumento pode ser o que ele é" (HEIDEGGER, 2012, p. 211). Assim, aquilo que o instrumento $e ́$ não reside em qualquer aspecto de sua realidade individual, mas se encontra antes na serventia e na eficácia que ele pode oferecer enquanto momento de uma totalidade instrumental configurada a cada vez segundo um projeto próprio ao ser-aí. Em Ser e Tempo, o ser das coisas que vêm ao encontro em nosso cotidiano é antes de tudo um ser relacional: é no interior do todo instrumental a partir do qual a coisa emerge que ela pode realizar aquilo que ela é, portanto, o seu ser é determinado a partir de redes de significação articuladas em torno de uma mesma função, cuja estrutura remissiva por sua vez dispõe cada coisa e o sentido que ela deve incarnar na execução do projeto do ser-aí - aquele que determina em última análise a articulação do todo.

Assim, o instrumento simplesmente não pode ser senão na relação que assume com outros entes no interior de uma mesma totalidade de significância. Aquele velho e inoperante martelo do clássico exemplo heideggeriano deixa de viger no momento em que não responde mais à exigência de serventia do todo instrumental do qual fazia parte: "Em termos rigorosos, um instrumento nunca 'é' isolado" (HEIDEGGER, 2012, p. 211). O martelo só é um martelo enquanto desaparecer na lida ocupada do carpinteiro que produz uma banqueta. Deste modo, mesmo num breve lance de olhos, podemos perceber que é um mesmo movimento que inaugura um lugar filosófico para o mundo da vida, quando se deixa de conceber as coisas como meros objetos e se passa a tratá-las a partir do relacionamento prático que se estabelece na simplicidade do cotidiano, mas que ao mesmo tempo abre também espaço para uma considerável perda de particularidade das coisas. Enquanto instrumento que responde a uma rede articulada segundo um fim que sempre diz respeito ao ser-aí, a coisa ela mesma não encontra um ser autônomo e independente, mas responde sempre à vida e ao caráter dos projetos do ser-aí - se é a utilidade que em última análise concede o ser de cada instrumento, então a coisa em sua individualidade é sempre descartável, substituível enquanto deixar de cumprir com a exigência de serventia (o martelo empregado nunca é aquele martelo em particular, mas é sempre a ferramenta para a realização de algo outro). Assim, a sua particularidade emerge no momento de interrupção da eficácia do instrumento, quer dizer, quando este deixa de ser propriamente um 
instrumento - à realização de seu ser pertence o seu próprio desaparecer na atividade que o revela. É certo que a intenção de Heidegger reside em desvelar o estatuto do mundo como uma estrutura fenomênica unitária, como o lugar onde as coisas emergem sempre a partir de uma totalidade de significância - é precisamente este o sentido do exemplo do quarto no qual o filósofo escreve, o todo partir do qual as coisas envolvidas na tarefa da escrita vêm à presença, ao mesmo tempo em que veem enfraquecida a sua própria individualidade:

De imediato, o-que-vem-de-encontro [...] é o quarto, o qual de sua parte não é aquilo que se acha 'entre quatro paredes', em um sentido espacial geométrico - mas instrumento-de-morar. A partir deste, mostra-se a arrumação do quarto e, nesta, cada um dos instrumentos "individuais" (HEIDEGGER, 2012, p. 211213).

Contudo, o sentido que as coisas cotidianas adquirem de dentro do mundo do ser-aí, em Ser e Tempo, é sempre também o próprio modo de ser destas mesmas coisas - é tudo o que elas podem ser: "O trato afeito cada vez ao instrumento é onde ele pode unicamente se mostrar genuinamente em seu ser" (HEIDEGGER, 2012, p. 213, grifo nosso). De algum modo, a fuga daquela concepção tradicional de totalidade que a toma como um simples amontoado de objetos acaba subjugando a individualidade da coisa ao todo que se quer tematizar, pois é somente no emprego do instrumento, cujo trato compreende sempre um caráter remissivo em que algo outro é visado, que este pode vir ao nosso encontro como um instrumento. A coisa enquanto instrumento, portanto, encontra seu modo de ser próprio na manualidade [Zuhandenheit], de modo que o seu significado reside unicamente na utilidade que adquire para aquele que a emprega, restando como mero objeto quando deixa de fazer parte de uma rede de significância e de serventia na ocupação do ser-aí: passa a ser uma "coisa-instrumento".

Deste modo, se a coisa pensada como instrumento no interior de Ser e Tempo é o sentido que ela adquire numa rede de significações articuladas segundo um critério pragmático, e se esse sentido por sua vez é sempre uma projeção da compreensão do ser-aí, então há uma clara dependência ontológica da coisa em relação ao ser-aí: o seu modo de ser é o de um instrumento para os projetos do ser-aí. "Dependência ontológica", aqui, não acarreta a perda de uma realidade externa ao ser-aí como se ele mesmo produzisse a coisa em sua mente, mas diz respeito ao modo particular como esta coisa vem à presença no mundo, o sentido que ela adquire no contexto total da interpretação de ser do ser-aí - a mediação semântica que se estabelece para a apreensão da coisa, como quer todo idealismo. O modo de ser do instrumento de Ser e Tempo, portanto, depende do modo de ser do ser-aí. Embora a temática da coisa como instrumento [Zeug], e de seu modo de ser como manualidade [Zuhandenheit], pretendesse claramente a 
construção de uma crítica radical à noção objetificada de coisa, assentada no modelo exclusivamente epistemológico da tradição, e de realizá-la em boa medida (já que introduz o âmbito de um relacionamento prático como ontologicamente primeiro, atuante mesmo no modo de se conceber a nossa essência e a nossa condição de ser-no-mundo), a pretensa superação da Modernidade em Ser e Tempo quanto à temática da coisa recai no mesmo problema da objetificação (ainda que em planos distintos, um epistêmico e outro prático): assim como a coisa representada se tornava mero objeto diante de um sujeito transcendental sempre primeiro, a coisa como instrumento continua subjugada à objetificação da lida ocupada do ser-aí, porque ela somente é capaz de realizar seu ser em plenitude enquanto atender à vontade humana. As coisas do mundo com as quais nos relacionamos existencial e pragmaticamente continuam sendo objetos para a nossa livre manipulação.

Assim, se por um lado Ser e Tempo contribui para a questão da essência do humano ao deixar de nos descrever a partir da subjetividade moderna como aquela consciência encapsulada e apartada do mundo, por outro lado, a correlação de mundo e ser-aí que alcança uma maior concretude para a questão da nossa essência (responsável pela integração do corpo à nossa autocompreensão), não deixa de incorrer no problema da metafísica quando concebe um ser humano que "manuseia" instrumentos no interior do mundo segundo a articulação de uma totalidade cujo fim é a realização de sua própria vontade. Um humano, portanto, cuja postura ${ }^{3}$ fundamental remonta ao caráter niilista intrínseco à Modernidade e já diagnosticado por Nietzsche: "As coisas do mundo do ser-aí têm seu Ser original como coisas do ser-aí; elas são o que são apenas como produtos ou expressões da 'vontade de potência' do ser-aí; isto é, a sua tentativa de preservar e aumentar a si mesmo dentro da vida para a qual fora lançado" (EDWARDS, 2002, p. 106). Este é precisamente o cerne da crítica que desejamos construir quanto ao aspecto metafísico de Ser e Tempo: aqui, a clássica tese do modo de ser das coisas do ser-aí como Zuhandenheit, quando examinada mais de perto, revela-se como companheira de uma concepção mais estruturante (para não dizer "subterrânea"), que conjuga a postura fundamental a partir de onde o ser humano se coloca no mundo e compreendo o todo e a si mesmo de uma única vez. Em outras palavras, o contexto pragmático e instrumental do modo de relacionamento do humano com as coisas do mundo revela uma atmosfera metafísica que anima a análise desde o princípio: é porque o ser-aí abdica de entidades absolutas externas ao mundo (as divindades da tradição filosófica, desde o motor

\footnotetext{
3 A noção de "postura", a partir de sua conotação especialmente prática, deve envolver tanto o modo de autocompreensão humana como o modo de relacionamento com o mundo das coisas, a partir do princípio de que se dá uma conexão entre ambos: a maneira como nos dispomos diante do mundo é reflexo do modo como compreendemos a nós mesmos e ao lugar que pretendemos ocupar no mundo.
} 
imóvel aristotélico até a Ideia hegeliana), buscando antes em seu modo de ser como compreensão que se dá sempre no mundo o solo decisivo para a construção de uma totalidade, que ele põe a si mesmo no mundo como figura de máxima centralidade. A entrada do ser-aí no mundo, portanto, dáse a partir de uma postura específica em que todas as coisas aparecem como meros objetos para o seu uso e manipulação.

\section{Uma postura de dominação e o sentido da Viravolta}

A ideia de uma postura fundamental que perpassaria as principais decisões metafísicas de uma época, sejam elas as interpretações fundamentais quanto à essência do humano e o lugar que este ocupa no mundo, ou o modo como o mundo ele mesmo e as suas coisas aparecem diante do homem, enquanto reflexos de um mesmo processo, é desenvolvida por Heidegger ainda na década de 30 no ensaio A época da imagem de mundo. Numa crítica à subjetividade moderna, Heidegger defende que a postura fundadora do homem moderno é a de sua entrada no mundo como a de um observador que se coloca diante de uma imagem para dela extrair uma vivência, isto é, numa posição que o distancia do próprio mundo. A descrição do processo de formação da Modernidade, deste modo, traz consigo o horizonte para a ideia de uma "postura de dominação" que pretendemos defender. No evento de fundação de toda época histórica, portanto, encontra-se uma decisão fundamental que se desenvolve por duas frentes: "A metafísica funda uma época à medida que ela lhe dá o fundamento da sua forma essencial [Wesensgestalt] por meio de uma determinada interpretação [Auslegung] do ente e uma específica concepção da verdade" (HEIDEGGER, 2005, p. 191). A partir daqui, o traço mais essencial da Modernidade pode ser identificado já na filosofia cartesiana com a postulação, de um lado, da interpretação do ente como objetividade do representar e, do outro, da concepção de verdade como certeza do representar. O fundamento metafísico da Modernidade em geral, portanto, repousa no relacionamento com o mundo a partir da representação [Vorstellung], isto é, enquanto representação - resta esclarecer como o representar adentra o mundo moderno e ao mesmo tempo lhe oferece uma fundação.

Conforme o que a própria noção de postura procura pensar, é uma mudança na autocompreensão humana, isto é, no modo como o homem adentra o mundo e aí estabelece o seu próprio lugar, que engendra ao mesmo tempo, e como resultado inevitável dessa atitude, uma transformada relação com o domínio dos entes. Em outras palavras, o modo como o homem moderno concebe a si mesmo se transforma no exato momento em que ele se torna sujeito, e isso em si já quer dizer: quando ele inaugura uma separação que toma espaço no entre de si e mundo. "Quando o homem, porém, converte-se no primeiro e autêntico subjectum, então isso significa: 
o homem torna-se aquele ente em que se funda todo o ente em sua forma de ser e em sua verdade. $O$ homem torna-se centro de referência do ente enquanto tal" (HEIDEGGER, 2005, p. 205). Na verdade, o próprio representar parece estar fundado neste movimento inaugural: ao se distanciar do mundo, tornando-o o objetivo que aparece como o representado para um sujeito, o que o homem propriamente faz é estabelecer uma posição para si a partir de onde tudo o mais é posto como diante de si já que representar [vorstellen] é sempre "pôr diante de si e direcionado a si". O momento de fundação da Modernidade, portanto, encontra-se no instante em que o homem põe a si mesmo diante do mundo, quer dizer, quando ele funda algo como uma posição, e neste mesmo gesto já estabelece tudo aquilo que permanece "do outro lado", tudo aquilo que se apresenta como uma contraposição a si. Se a posição humana no mundo inaugura uma contraposição àquele que assim se posta, então a objetificação do ente é sempre seguida por uma intensa subjetivação na outra via - um é a possibilidade do outro.

A atividade de representar significa acima de tudo que o ente em sua totalidade só vem a ser a partir do sujeito que já sempre o pôs diante de si e voltado para si, isto é, quando o ente se encontra dominado pelo homem no seu jogo de pôr e contrapor: "O ente em totalidade agora é entendido assim que, primeiramente e apenas é, à medida que é posto pelo homem representante-producente" (HEIDEGGER, 2005, p. 207). No mesmo passo, se a interpretação moderna do ente em seu todo corresponde à representação, o que ao mesmo tempo já significa que o mundo se tornou ele mesmo uma imagem diante de um sujeito, então o nosso próprio modo de relacionamento com o mundo das coisas se encontra perpassado por este mesmo pressuposto: tudo já está sempre diante de nós, e isto quer também dizer, disposto como o já sempre disponível para o nosso uso e proveito. "Inicia-se aquela maneira de ser do homem, a qual ocupa o âmbito das capacidades humanas como o espaço de medida e execução da dominação do ente em totalidade" (HEIDEGGER, 2005, p. 209, grifo nosso). Assim, a conquista do mundo como imagem é o instalar o ente em seu todo como uma coisa que já sempre está ali para mim, segundo a integração do que denominamos uma postura de dominação de um lado, e de outro, a condição de dominado de todo o ente - assim, novamente avistamos o problema da objetificação metafísica.

$\mathrm{O}$ processo em que de um lado o mundo torna-se imagem e do outro o homem torna-se sujeito, portanto, é um e o mesmo processo em que se constitui a postura fundamental do homem moderno na qual a lida com o ente constitui desde o princípio um exercício de dominação. Como o mesmo diagnóstico quanto à objetificação metafísica já fora feito em relação a Ser $e$ Tempo, a partir da análise dos conceitos de instrumento [Zeug] e manualidade [Zuhandenheit], nossa proposta é a de que essa mesma postura descrita por Heidegger nos anos 30 como fundadora da Modernidade, onde 
um projeto sistemático de domínio do ente teria início, pode também ser encontrada em porções de Ser e Tempo, ainda que de modo subterrâneo, isto é, não explicitado para o próprio autor. É possível constatar a vigência dessa postura de dominação numa passagem surpreendente em que Heidegger descreve o modo de abertura da natureza como a de um ente disponível ao ser-aí, quer dizer, a sua doação como mais um dos instrumentos de Ser $e$ Tempo: "Mas natureza não deve ser entendida aqui como o ainda só subsistente, nem também como força-da-natureza. A mata é reserva florestal, o monte, pedreira, o rio, energia hidráulica, o vento é vento "nas velas"” (HEIDEGGER, 2012, p. 217). Em outras palavras, a própria natureza permanece à mão, apresenta-se ao ser-aí como uma fonte inesgotável de recursos utilizáveis, cuja constituição de ser responde unicamente à manutenção da nossa vida no planeta. A postura de dominação a que fazemos referência pode assim ser identificada no trato ocupado com tudo o que vem ao nosso encontro: pois as coisas com que nos relacionamos de modo prático em nosso cotidiano, no contexto de Ser e Tempo, obedecem ao modo de ser do instrumento, cumprem a exigência de se tornarem objetos para a vontade de dominação do ser-aí ${ }^{4}$.

No mesmo caminho, Edwards (2002, p. 105) desenvolve uma leitura acerca do tratamento metafísico das coisas do mundo em Ser e Tempo a partir da tese de que esse modo de relacionamento excessivamente instrumental resulta na diminuição do pathos ordinário destas mesmas coisas. Uma espécie de "depotenciação" das coisas cotidianas, portanto, decorrente da compreensão de seu modo de ser como instrumentos para o ser-aí, que se dá como uma perda de pathos no sentido de que aí se esvai aquela "pregnância" ordinária do encontrar-se constantemente em meio às coisas, dirigindo-lhes juízos, intenções, afetos: numa vivência plena de pathos, a caneca de chá sobre a mesa de trabalho nunca é um objeto qualquer comprado na loja de utensílios domésticos, mas é aquela velha caneca na qual está impresso o símbolo do clube de futebol preferido. Antes disso, a consequência a que assistimos aflorar no interior de Ser e Tempo é a de uma abertura cotidiana das coisas como "meros instrumentos" - para subverter a terminologia heideggeriana -, como coisas descartáveis e intercambiáveis que "valem" unicamente pela função que executam: "Na abordagem 'pragmática' de Ser e Tempo, as coisas são desvalorizadas, despojadas de seu pathos ordinário, assim como é a vida dentro da qual aquelas coisas têm o seu Ser original" (EDWARDS, 2002, p. 109). Como mostra Edwards, é o próprio modo de vida subjacente à lida cotidiana com as coisas que enseja em última análise essa diminuição de pathos, em outras

\footnotetext{
${ }^{4} \mathrm{O}$ caráter objetificador do relacionamento do ser-aí com a natureza é tão flagrante nesta passagem, que o reconhecimento do rio como fonte de energia hidráulica, por exemplo, pode ser claramente aproximado com a crítica à era da técnica que Heidegger irá desenvolver nos anos 50: aí, a dominação humana em nível planetário compreende a disponibilização de todos os entes como "fontes de reserva".
} 
palavras, o modo de vida que subjaz à estruturação ontológica do critério pragmático de Ser e Tempo é ela mesma uma vida que enfrenta a diminuição de seu pathos ordinário. Pode-se afirmar, por fim, que o modo de vida particular que sustenta a articulação do conceito de instrumento em Ser e Tempo é um modo de vida essencialmente objetificador e instrumental, assim como a postura fundadora da metafísica moderna. Contudo, essa concepção não é expressa no próprio discurso da obra, permanecendo antes rente às estruturas de seu todo, como o fundo histórico a partir do qual emerge Ser e Tempo.

Por fim, talvez possamos nos utilizar do próprio testemunho de Heidegger se quisermos observar em retrospectiva o surgimento do problema da metafísica no interior de seu próprio pensamento: para o filósofo, a incompletude de Ser e Tempo se deve à sua pretensão de refundar toda uma tradição a partir da recolocação da questão mais fundamental do pensamento, tendo de fazê-lo, contudo, a partir da mesma linguagem sob a qual assentam aquelas categorias que se desejava "desconstruir" (segundo a ideia da Destruktion). Este é precisamente o problema da linguagem de Ser e Tempo que Heidegger comenta em Sobre o humanismo. Aqui, parece constar o reconhecimento de que o caráter essencialmente pragmático da linguagem de Ser e Tempo (porque devedora daquele relacionamento prático sempre primeiro que analisamos acima, a partir de onde a tarefa da linguagem cumpre em tão somente "expressar" esse relacionamento), mais a sua estrutura designativa (porque se trata da mesma linguagem da tradição, onde a possibilidade do significado reside no objeto referido no mundo), teriam dificultado a execução do projeto de Ser e Tempo, fazendo-o recair em variados processos de entificação; em outras palavras, teriam constituído um verdadeiro bloqueio para o dizer do Ser que aí estava em questão preparar: "Esta viravolta não é uma mudança do ponto de vista de Ser e Tempo; mas, nesta viravolta, o pensar ousado alcança o lugar do âmbito a partir do qual Ser e Tempo foi compreendido e, na verdade, compreendido a partir da experiência fundamental do esquecimento do ser" (HEIDEGGER, 1983, p. 156). Isto é, o impulso maior para o que vem posteriormente a Ser e Tempo assenta no reconhecimento de que a primeira obra do filósofo não realizou o salto em direção ao dizer do Ser, ou então permaneceu incapaz de realizar o salto para fora da metafísica.

Ainda no contexto de Sobre o humanismo, Heidegger explica o problema da metafísica como o processo histórico em que não se levanta a questão acerca da verdade do Ser, o que quer dizer que não se pergunta pela condição de possibilidade a partir de onde todo ente emerge: "Para toda percepção do ente em seu ser, o ser mesmo já se iluminou e acontece historialmente em sua verdade" (HEIDEGGER, 1983, p. 154). Essa abertura primordial de Ser que já sempre aconteceu para nós é o que em última análise guia a nossa interpretação do ente no seu todo, o ser do ente por sua vez corresponde a um único horizonte de desvelamento, aquele do próprio 
ente e de sua época, de modo que "entificar" o Ser é pensá-lo a partir dessa estrutura objetificada e não a partir da sua própria verdade, que permanece velada a cada novo desencobrimento do ente. Na metafísica, portanto, aquilo que funda é o que também permanece inquestionado. A partir deste contexto, o maior problema envolvendo a linguagem na execução do projeto heideggeriano de crítica à metafísica se encontrava na exigência de fazê-lo a partir das próprias bases filosóficas de então, isto é, segundo o uso de expressões familiares à dicção filosófica corrente (num esforço para uma exposição suficientemente clara do caráter negativo de sua empreitada, e que ao mesmo tempo pudesse abandonar o paradigma da subjetividade). Assim, interpretar a tarefa da questão do Ser, nos termos específicos a que se propunha Ser e Tempo, a partir do sentido habitual de expressões metafísicas é incorrer inevitavelmente em erros e confusões, e mais do que isso, é furtar-se à tentativa de repensar a tradição naquilo que ela manteve inaudito para si mesma:

\begin{abstract}
A tarefa de repetir e acompanhar, de maneira adequada e suficiente, este outro pensar que abandona a subjetividade foi sem dúvida dificultada pelo fato de, na publicação de Ser $e$ Tempo, eu haver retido a Terceira Seção da Primeira Parte [...]. Aqui o todo se inverte. A seção problemática foi retida, porque o dizer suficiente desta viravolta fracassou e não teve sucesso com o auxílio da linguagem da Metafísica (HEIDEGGER, 1983, p. 156).
\end{abstract}

A saída para fora da metafísica não pode se realizar de dentro de sua própria linguagem. $\mathrm{O}$ dizer que entifica, que se relaciona com a linguagem de um modo exclusivamente instrumental, que trata a totalidade como uma teoria de objetos e que a representa como um ente maximamente determinado e tornado absoluto, este dizer representa desde o primeiro momento um entrave para a questão do Ser, é o que está posto para ser superado. A Viravolta, deste modo, surge como o reconhecimento da necessidade de um novo dizer que possa ultrapassar os bloqueios oferecidos por uma linguagem que se mostra ela mesma metafísica - um novo dizer que cumpra a tarefa de uma inversão do caminho, sem que o eixo central da proposta se perca: o pensamento heideggeriano se volta para si mesmo com o intuito de reformular sua questão central, a questão do Ser, que permanece em essência inalterada, mas precisa antes de tudo procurar nesse giro sobre si mesma um novo horizonte conceitual que possa salvaguardar a interrogação heideggeriana de influxos metafísicos. Neste mesmo passo, o sentido da Viravolta emerge junto ao reconhecimento da necessidade de um aprofundamento do projeto de crítica à metafísica, que no interior da leitura que desenvolvemos acerca de Ser e Tempo, compreende essencialmente a tarefa de se conceber um modo de relacionamento renovado do humano com o mundo e as suas coisas. 


\section{Considerações finais}

O modo de Heidegger expressar o problema para o qual pretendemos ter apontado, aquele do tratamento objetificado das coisas cotidianas, segue a direção de enxergar aí mais uma faceta do procedimento metafísico por excelência: o esquecimento do Ser - quer dizer, também Ser e Tempo teria incorrido no problema de não questionar a coisa em seu ser de modo suficiente e de submetê-la a uma interpretação prévia, o que antes de tudo bloqueia a emergência do que ela é para além do seu uso e serventia, para além do que desejamos que ela seja. A ideia desse giro sobre si mesmo evocada pela Viravolta, articulada, sobretudo, no interior da linguagem e da necessidade de uma ruptura epistemológica que possa dar conta de conceitos não-metafísicos, é o que permite que o projeto heideggeriano de crítica à metafísica dê um passo à frente em direção à ruptura com a objetificação, e ao mesmo tempo um passo atrás, no sentido de avaliar em retrospectiva as fraturas da preparação de sua questão central, a questão do Ser. É o próprio Heidegger que aponta para o problema da linguagem de Ser e Tempo, como vimos junto ao diagnóstico de Sobre o humanismo, e ainda que a objetificação do instrumento não seja apontada textualmente, podemos construir nossa análise a partir das ferramentas que o exercício heideggeriano de crítica à metafísica nos legou: é aquela mesma postura de dominação identificada no processo de formação da Modernidade que anima em boa medida a estruturação ontológica da relação homem-coisa no contexto pragmático de Ser e Tempo, quando esta é resumida ao critério da utilidade e disponibilidade.

Deste modo, compreendemos que a Viravolta heideggeriana pode ser lida a partir da mudança de atitude do filósofo em relação à crítica da metafísica, quando volta seu projeto contra si mesmo e aí identifica a dificuldade de se desvincular dos preconceitos da tradição que insistem em determinar uma posição tanto distanciada como privilegiada para o homem em sua relação com o mundo - em outras palavras, o diagnóstico do caráter metafísico de Ser e Tempo encontra seu fundamento de modo imanente, isto é, a partir da própria obra heideggeriana. A Viravolta pode aparecer agora como a inflexão a partir da qual Heidegger abandona aquela compreensão das coisas de nosso mundo determinada por um contexto exclusivamente pragmático e instrumental, para dar espaço a uma postura que possa rejeitar a objetificação de si, dos outros seres humanos, e das coisas com que garantimos nossa sobrevivência neste planeta. A tarefa de um aprofundamento da crítica à metafísica que emerge como um dos sentidos da Viravolta, contudo, só pode tomar espaço a partir do momento em que se reconhece a presença do problema e a necessidade imanente de sua superação. 
A releitura do conceito de instrumento de Ser e Tempo, mais a estrutura pragmática do mundo do ser-aí que ele articula, tendo o revelado em seu caráter objetificador e subjugado a uma postura de dominação própria ao homem moderno, abre caminho para que se explicite o sentido da Viravolta como a passagem para uma nova proposta de crítica à metafísica: a tarefa de superar tanto o relacionamento objetificado com as coisas de nossos mundos cotidianos como a postura moderna de dominação. Com a Viravolta, portanto, o projeto heideggeriano de crítica à metafísica passa a significar a investida por uma nova postura para o ser humano, a partir de uma ideia central para o contexto da filosofia de Heidegger a partir da década de 40: é preciso deixar que as coisas simplesmente sejam. De uma só vez, uma nova compreensão do humano e, como consequência, uma espécie de nova "entrada" no mundo (como uma refundação do lugar que queremos ocupar), junto com um modo de relacionamento com as coisas cotidianas que abdique daquela vontade de dominação, são todos movimentos conceituais que devem conduzir a obra heideggeriana rumo à articulação de uma postura pós-metafísica ${ }^{5}$.

\section{Referências bibliográficas}

EDWARDS, James C. Poetic dwelling on the earth as a mortal. In: DREYFUS, H; WRATHALL, M. (Ed.). Heidegger reexamined: art, poetry, and technology. Vol. 3. New York; London: Routledge, 2002, p. 105-148. GIACOIA JUNIOR, Oswaldo. Heidegger urgente: introdução a um novo pensar. São Paulo: Três Estrelas, 2013.

HEIDEGGER, Martin. A época da imagem de mundo. Tradução de Paulo Rudi Schneider. In: SCHNEIDER, P. R. O outro pensar: sobre que significa pensar? e a época da imagem de mundo, de Heidegger. Ijuí: Ed. Unijuí, 2005, p. 191-232.

Discourse on thinking. Tradução de John M. Anderson e E. Hans Freund. New York: Harper and Row, 1966.

Ensaios e conferências. Tradução de Emmanuel Carneiro Leão, Gilvan Fogel, Márcia Sá Cavalcante Schuback. 6. ed. Petrópolis: Vozes, 2010.

Ser e Tempo. Tradução de Fausto Castilho. Campinas, SP: Editora da Unicamp; Petrópolis, RJ: Editora Vozes, 2012.

Serenidade. Lisboa: Instituto Piaget, 2002.

Sobre o humanismo. In: Conferências e escritos filosóficos. Tradução de Ernildo Stein. 2. ed. São Paulo: Abril Cultural, 1983, p. 147175 .

\footnotetext{
${ }^{5}$ Essa postura é pensada na obra tardia de Heidegger pela via da noção de Serenidade [Gelassenheit], onde o relacionamento humano com as coisas do mundo consiste antes de tudo em deixá-las vir ao encontro do modo em que elas mesmas são. Essa postura dita pósmetafísica deve nos ocupar no prosseguimento de nossa pesquisa.
} 
STEIN, Ernildo. Pensar é pensar a diferença: filosofia e conhecimento empírico. 2. ed. Ijuí: Editora Unijuí, 2006. 